\title{
SISTEM PENDUKUNG KEPUTUSAN PENENTUAN RUMAH TANGGA MISKIN PADA DESA CIBANGKONG DENGAN METODE WASPAS
}

\author{
Sugeng Riyadi ${ }^{1}$, Tuti Haryanti ${ }^{2}$, Laela Kurniawati ${ }^{3}$ \\ Program Studi Sistem Informasi \\ STMIK Nusa Mandiri \\ www.nusamandiri.ac.id \\ ${ }^{1}$ sugengriyadi484@gmail.com, 2tuti@nusamandiri.ac.id, ${ }^{3}$ laela@nusamandiri.ac.id
}

\begin{abstract}
Abstrak
Pada era sekarang ini, berbagai kegiatan proses bisnis membutuhkan penerapan teknolog informasi. Pengambilan keputusan merupakan salah satu kegiatan proses bisnis yang dapat dibantu dengan adanya teknologi. Penentuan keluarga miskin adalah suatu masalah yang rumit karena banyak kriteria yang harus terpenuhi untuk menentukan sebuah keluarga miskin dan layak menerima bantuan penanganan kemiskinan. Oleh karena itu dibuatlah sistem pendukung keputusan dengan metode Weighted Aggregated Sum Product Assesment (WASPAS) dengan kriteria yang telah ditetapkan kemudian diimplementasikan dengan menggunakan Visual Basic .Net. Sampel yang digunakan adalah warga Desa Cibangkong sebanyak 89 Rumah Tangga yang terdaftar mengajukan bantuan pemerintah. Hasil penelitian diperoleh 12 rumah tangga sangat miskin, 28 rumah tangga miskin, 38 rumah tangga rentan miskin dan 11 rumah tangga tidak miskin. Dengan sistem pendukung keputusan metode WASPAS ini pengolahan data akan menjadi lebih efektif dan efisien karena proses penilaian dan pembuatan laporan menjadi cepat. Pegawai hanya memasukan data penduduk, data kriteria dan data penilaian penduduk, sedangkan proses perhitungan dan pembuatan laporan dilakukan oleh sistem.
\end{abstract}

\section{Kata Kunci: Metode WASPAS, Rumah Tangga Miskin, Sistem Penunjang Keputusan}

\begin{abstract}
In the current era, various business process activities require the application of information technology. Decision making is one of the business process activities that can be helped by the existence of technology. Determining poor families is a complex problem because many criteria must be met to determine poor families and deserve assistance in dealing with poverty. Therefore, a decision support system is made using the Weighted Aggregated Sum Product Assessment (WASPAS) method with predetermined criteria and then implemented using Visual Basic.Net. The sample used was 89 residents of Cibangkong Village who were registered to apply for government assistance. The results of the study obtained 12 very poor households, 28 poor households, 38 poor vulnerable households and 11 non-poor households. With a decision support system, the WASPAS method in processing data will be more effective and efficient because of the process of evaluating and making quick reports. Employees only enter population data, criteria data and population assessment data, while the process of calculating and reporting is done by the system.
\end{abstract}

\section{Keywords: WASPAS Method, Poor Households, Decision Support System}

\section{PENDAHULUAN}

Pada era sekarang ini, berbagai kegiatan proses bisnis membutuhkan penerapan teknologi informasi. Dengan penerapan teknologi informasi diharapkan proses bisnis akan terbantu dengan sebuah sistem yang sesuai dengan pemakainya, sehingga dalam kegiatan proses bisnis sehari-hari dapat dilakukan dengan lebih cepat dan lebih baik dari sebelumnya. Dengan begitu teknologi informasi merupakan salah satu kebutuhan yang sangat penting untuk menunjang aktivitas organisasi. Menurut (Pardiansyah, 2015), mengatakan "teknologi informasi (IT) saat ini sudah menjadi kebutuhan yang sangat penting bagi hampir semua organisasi perusahaan karena dipercaya dapat membantu meningkatkan efektivitas dan efisiensi proses bisnis perusahaan".

Pengambilan keputusan merupakan salah satu kegiatan proses bisnis yang dapat dibantu dengan adanya teknologi. Dalam menentukan satu pilihan dari beberapa alternatif, sebuah organisasi perlu mempertimbangkan beberapa kriteria yang ada. Pengambil keputusan harus mengambil keputusan dengan cepat dan akurat (irfansyah \& Sunoto, 2015). Pengambilan keputusan harus dilakukan secara cepat, teliti, tepat sasaran dan dapat 197 
keberhasilan dalam pengambilan keputusan di kemudian hari (Sugiarti, Nahulae, Panggabean, \& Sianturi, 2018). Diharapkan dengan adanya sistem penunjang keputusan pengambil keputusan dapat terbantu dalam menentukan pilihan yang akan diambil.

Kemiskinan merupakan kondisi sosial masyarakat yang tidak mempunyai kemampuan dalam memenuhi kebutuhan pokok yang layak bagi kemanusiaan (Muzakkir, 2017). Kebutuhan, kekurangan dan kesulitan merupakan masalah yang berhubungan dengan kemiskinan. Kondisi kemiskinan tercipta karena tidak adilnya atau tidak meratanya dalam pelaksanaan pembangunan. Kemiskinan saat ini semakin meningkat dan terjadi ketidakstabilan kondisi ekonomi yang menyebabkan menurunnya tingkat pendapatan masyarakat sehingga masyarakat tidak lagi memenuhi kebutuhannya sendiri (Setiani, 2017).

Dalam rangka pembangunan pengentasan kemiskinan dilakukan program penanggulangan kemiskinan seperti program Kartu Indonesia Sehat (KIS), Kartu Indonesia Pintar (KIP), Program Keluarga Harapan (PKH), Bantuan Pangan Non Tunai (BPNT) dan Pembangunan Rumah Tidak Layak Huni (RTLH). Agar program tersebut terlaksana dengan adil dan merata makan perlu dilakukan pendataan terhadap rumah tangga miskin, data kemiskinan merupakan suatu hal yang penting karena menjadi pertimbangan dalam proses perencanaan program penanggulangan kemiskinan dan pendataan tersebut untuk memudahkan dalam pelaksanaan program pembangunan.

Dalam pelaksanaan pendataan keluarga miskin Pemerintah Desa Cibangkong mengalami kesulitan karena dalam penentuan rumah tangga miskin memiliki kriteria yang banyak sehingga butuh waktu lama untuk penentuan rumah tangga miskin. Penentuan keluarga miskin adalah suatu masalah yang rumit (Indrawati, Hyoscyamina, Qonitatin, \& Abidin, 2014), karena banyaknya kriteria yang harus terpenuhi untuk menentukan sebuah keluarga miskin dan layak menerima bantuan penanganan kemiskinan (Saputra, Kartini, \& Soesanto, 2016). Pada akhir bulan Maret 2019 pemerintah Desa Cibangkong menerima pengajuan 748 data rumah tangga yang harus di validasi agar nantinya penentuan keluarga miskin sesuai dengan kriteria-kriteria yang sudah ditentukan pemerintah. Dengan banyaknya kriteria dan banyaknya pula keluarga untuk diseleksi membuat Pemerintah Desa Karang Rejo mengalami kesulitan dalam penentuan rumah tangga miskin (Saputra, Kartini, \& Soesanto, 2015). Kriteria-kriteria yang disurvei tidak sesuai dengan ketentuan pemerintah (Lubis, Nadeak, \& Hondro, 2017).
Berdasarkan masalah di atas, penulis merancang sistem pendukung keputusan penentuan rumah tangga miskin pada Desa Cibangkong dengan metode (WASPAS). Metode Weighted Aggregated Sum Product Assesment WASPAS merupakan metode yang mengambil keputusan dengan efektif atas persoalan yang kompleks dengan menyederhanakan dan mempercepat proses pengambilan keputusan untuk memecahkan masalah tersebut (Sianturi, Siburian, Hutagaol, \& Sahir, 2018). Tujuan penelitian ini sebagai sistem pendukung keputusan,penilaian penentuan rumah tangga miskin sesuai dengan kriteria yang telah ditentukan pemerintah dan bantuan dari pemerintah akan tepat sasaran.

\section{METODE PENELITIAN}

a. Metode Weighted Aggregated Sum Product Assesment (WASPAS)

Menurut (Handayani \& Marpaung, 2018), "Metode WASPAS merupakan metode yang mengurangi kesalahan-kesalahan atau mengoptimalkan dalam penaksiran atau pemilihan nilai tertinggi dan terendah". Metode ini merupakan kombinasi unik dari pendekatan MCDM yaitu model jumlah tertimbang (Weight Sum Model /WSM) dan model produk tertimbang (Weight Product Model/WPM). Pada awalnya membutuhkan normalisasi linier dari elemen matriks keputusan dengan menggunakan dua persamaan.

Langkah-langkah metode Weighted Aggregated Sum Product Assesment (WASPAS) sebagai berikut:

1) Menentukan normalisasi matriks dalam pengambilan keputusan

$\mathrm{X}=\left[\begin{array}{cccc}x 11 & x 12 & \ldots & x 1 n \\ x 12 & x 22 & \ldots & x 2 n \\ \ldots & \ldots & \ldots & \ldots \\ x m 1 & x m 2 & \ldots & x 3 n\end{array}\right]$

Jika nilai maksimal dan minimal ditentukan maka persamaan menjadi sebagai berikut:

a. Jika kriteria benefit maka:

$$
X i j=\frac{x i j}{M a x i X i j}
$$

b. Jika kriteria cost maka:

$$
X i j=\frac{x i j}{\text { MiniXij }}
$$

2) Menghitung nilai normalisasi matriks dan bobot WASPAS dalam pengambilan keputusan.

$$
\mathrm{Q}=0.5 \sum_{j=1}^{n} X i j W j+0.5 \prod_{j=1}(X i j)^{w j}
$$


Keterangan

0.5 adalah ketetapan

$Q_{i} \quad=$ Nilai dari $Q$ ke $i$

$X_{i j W}=$ Perkalian nilai $X_{i j}$ dengan bobot $w$

Benefit = Jika nilai terbesar adalah terbaik Cost $=$ Jika nilai terkecil adalah terbaik

a. Instrumen Penelitian

Instrumen yang digunakan dalam penelitian ini antara lain:

1). Pedoman Wawancara

Pedoman wawancara ini berisi uraian penelitian yang dituangkan dalam bentuk daftar pertanyaan agar proses wawancara dapat berjalan dengan baik dan memperoleh informasi lebih mendalam mengenai penilaian rumah tangga miskin yang ada di Desa Cibangkong.

2). Pedoman Observasi

Pedoman observasi digunakan untuk membuat deskripsi singkat yang berkenaan dengan perilaku yang diamati dan kegiatan yang mungkin diperlihatkan oleh individu-individu yang diamati. Pedoman observasi pada penelitian ini berisi daftar rumah tangga di Desa Cibangkong yang mengajukan sebagai rumah tangga miskin dan daftar penilaian rumah tangga miskin.

\section{b. Metode Pengumpulan Data}

Metode pengumpulan data yang digunakan dalam penelitian ini sebagai berikut:

1). Observasi

Penulis mengumpulkan data dengan mencari informasi melalui pengamatan secara langsung pada Kantor Pemerintah Desa Cibangkong dan pencatatan secara sistematis yang berkaitan dengan proses penentuan rumah tangga miskin yang ada di Desa Cibangkong.

2). Wawancara

Penulis mengumpulkan data informasi melalui tanya jawab dan diskusi secara langsung dan secara terstruktur dengan pihak-pihak yang dapat memberi keterangan terkait proses penentuan rumah tangga miskin yang ada di Desa Cibangkong.

3). Studi Pustaka

Penumpulan data sekunder pada penelitian ini dilakukan dengan mengumpulkan data dan informasi melalui studi pustaka yaitu data-data yang diperoleh melalui buku-buku referensi, jurnal-jurnal penelitian terkait maupun ebook yang berhubungan dengan permasalahan yang diteliti guna mendukung penulisan skripsi ini.

c. Populasi
Populasi dalam penelitian ini adalah seluruh rumah tangga pemohon bantuan pemerintah terdaftar di Desa Cibangkong. Di mana jumlah pemohon rumah tangga miskin yang terdaftar berjumlah 748 keluarga.

d. Sampel Penelitian

Dalam menentukan ukuran sampel dari populasi rumah tangga miskin yang ada di Desa Cibangkong penulis menggunakan rumus Slovin

$\mathrm{n}=\mathrm{N} /\left(1+\left(\mathrm{Ne}^{\wedge} 2\right)\right)$

Dimana:

$\mathrm{n}=$ Jumlah sampel

$\mathrm{N}=$ Jumlah Populasi

e = Batas toleransi kesalahan (Error tolerance).

$\left.\mathrm{n}=748 /\left(1+\left(748^{*} \llbracket 0.1\right] \wedge 2\right)\right)$

$\mathrm{n}=748 /(1+(748 * 0.01))$

$\mathrm{n}=748 /(1+7.48)$

$\mathrm{n}=748 / 8.48$

$\mathrm{n}=88.20$

Dengan menggunakan rumus Slovin yang memiliki nilai kritis atau prosentase kelonggaran ketidakterikatan sebesar 10\%, maka jumlah yang dibutuhkan adalah 89 rumah tangga miskin yang ada di Desa Cibangkong.

e. Metode Analisis Data

Untuk mencapai tujuan penelitian ini, maka metode analis data yang digunakan untuk menentukan rumah tangga miskin menggunakan metode Weighted Aggregated Sum Product Assesment (WASPAS), berdasarkan perhitungan dengan metode ini menghasilkan peringkatan atau ranking yang terdiri dari empat kriteria yaitu sangat miskin, miskin, rentan miskin dan tidak miskin. Nilai kriteria dapat dilihat pada tabel 1

Tabel 1. Nilai Status Kemiskinan

\begin{tabular}{ll}
\hline \multicolumn{1}{c}{ Nilai } & \multicolumn{1}{c}{ Status } \\
\hline $0.910>=$ Nilai Ranking $<=1$ & Sangat Miskin \\
$0.810>=$ Nilai Rangking $<9.10$ & Miskin \\
$0.710>=$ Nilai Ranking $<0.810$ & Rentan Miskin \\
$0.510>=$ Nilai Ranking $<0.710$ & Tidak Miskin \\
\hline
\end{tabular}

Sumber: (Lestari \& Targiono, 2017)

\section{HASIL DAN PEMBAHASAN}

\section{A. Analisa Kebutuhan Perangkat Lunak}

Analisa kebutuhan digunakan untuk menentukan kebutuhan secara lengkap, maka kebutuhan dibagi menjadi dua bagian yaitu kebutuhan fungsional dan kebutuhan non fungsional

1). Kebutuhan Fungsional 
a) Admin dapat melihat, menambah, mengubah dan menghapus data pengguna atau petugas.

b) Admin atau Operator dapat menambah periode seleksi.

c) Admin dapat melihat, menambah, mengubah dan menghapus data penduduk.

d) Admin dapat melihat, menambah, mengubah, menghapus data kriteria dan bobot kriteria beserta rincian nilai kriteria.

e) Admin atau operator dapat memasukan nilai data penduduk.

f) Sistem dapat menghitung nilai data penduduk dengan menggunakan metode WASPAS.

g) Sistem dapat menghasilkan laporan akhir penilaian penduduk beserta keputusannya.

2). Kebutuhan Non Fungsional

a). Kinerja

Peningkatan terhadap sistem yang baru dalam mengolah data dan menampilkan informasi secara keseluruhan dalam menyelesaikan proses yang ditangani. Adapun kinerja yang diharapkan dari sistem ini adalah Waktu yang dibutuhkan untuk penilaian penduduk lebih cepat dan mempermudah pembuatan laporan hasil penilaian penduduk beserta keputusannya.

b). Keamanan (Security)

Adapun kebutuhan yang mencakup dengan keamanan antara lain pengguna diberikan hak akses yang berbeda-beda dan sistem aplikasi dilengkapi dengan nama (username) dan kata sandi (password).

c). Informasi

Informasi yang dapat dilakukan oleh pengguna pada sistem ini berisi hal-hal yang dilakukan, antara lain: Digunakan untuk memberi peringatan untuk pengguna jika data yang dimasukkan tidak lengkap. Digunakan untuk menginformasikan pengguna apabila nama (username) dan kata sandi (password) yang dimasukkan salah, maka sistem akan menampilkan informasi bahwa data petugas tidak terdaftar.

\section{B. Pengolahan Data dan Penghitungan Dengan Menggunakan Metode WASPAS}

Proses penentuan rumah tangga miskin pada Desa Cibangkong dengan menggunakan metode Weighted Aggregated Sum Product Assesment (WASPAS) diperlukan perhitungan nilai kriteriakriteria dan bobot masing-masing kriteria sehingga didapatkan alternatif terbaik.
Tabel 1. Bobot Kriteria

\begin{tabular}{|c|c|c|c|}
\hline Kode & Keterangan & $\begin{array}{l}\text { Bob } \\
\text { ot }\end{array}$ & Keterangan \\
\hline K1 & $\begin{array}{l}\text { Status bangunan } \\
\text { tempat tinggal yang } \\
\text { ditempati }\end{array}$ & $5 \%$ & Benefit \\
\hline $\mathrm{K} 2$ & $\begin{array}{l}\text { Status lahan tempat } \\
\text { tinggal yang ditempati }\end{array}$ & $5 \%$ & Benefit \\
\hline K3 & Luas lantai & $5 \%$ & Benefit \\
\hline K4 & Jenis lantai terluas & $\begin{array}{l}10 \\
\%\end{array}$ & Benefit \\
\hline K5 & Jenis dinding terluas & $\begin{array}{l}10 \\
\%\end{array}$ & Benefit \\
\hline K6 & Jenis atap terluas & $\begin{array}{l}10 \\
\%\end{array}$ & Benefit \\
\hline K7 & Jumlah kamar tidur & $5 \%$ & Benefit \\
\hline K8 & Sumber air minum & $5 \%$ & Benefit \\
\hline K9 & $\begin{array}{l}\text { Cara memperoleh air } \\
\text { minum }\end{array}$ & $5 \%$ & Benefit \\
\hline K10 & $\begin{array}{l}\text { Sumber penerangan } \\
\text { utama }\end{array}$ & $5 \%$ & Benefit \\
\hline K11 & $\begin{array}{l}\text { Bahan bakar atau } \\
\text { energi utama untuk } \\
\text { memasak }\end{array}$ & $5 \%$ & Benefit \\
\hline K12 & $\begin{array}{l}\text { Penggunaan fasilitas } \\
\text { tempat buang air } \\
\text { besar }\end{array}$ & $5 \%$ & Benefit \\
\hline K13 & Jenis kloset & $5 \%$ & Benefit \\
\hline K14 & $\begin{array}{l}\text { Tempat pembuangan } \\
\text { akhir tinja }\end{array}$ & $5 \%$ & Benefit \\
\hline K15 & $\begin{array}{l}\text { Ijazah tertinggi yang } \\
\text { dimiliki kepala rumah } \\
\text { tangga }\end{array}$ & $5 \%$ & Benefit \\
\hline K16 & $\begin{array}{l}\text { Pekerjaan utama } \\
\text { kepala rumah tangga }\end{array}$ & $5 \%$ & Benefit \\
\hline K17 & $\begin{array}{l}\text { Total harga aset yang } \\
\text { dimiliki }\end{array}$ & $5 \%$ & Benefit \\
\hline
\end{tabular}

Menentukan matriks keputusan

$\left[\begin{array}{ccccccccccccccccc}25 & 25 & 15 & 20 & 10 & 10 & 15 & 15 & 30 & 30 & 20 & 30 & 15 & 25 & 30 & 30 & 40 \\ 25 & 25 & 30 & 20 & 20 & 10 & 20 & 15 & 30 & 30 & 20 & 30 & 30 & 25 & 30 & 30 & 40 \\ 25 & 25 & 25 & 15 & 20 & 10 & 15 & 15 & 30 & 30 & 10 & 15 & 15 & 20 & 30 & 30 & 20 \\ 25 & 25 & 20 & 10 & 10 & 10 & 20 & 15 & 30 & 30 & 10 & 30 & 30 & 25 & 30 & 20 & 20 \\ 25 & 25 & 20 & 20 & 15 & 10 & 25 & 10 & 30 & 30 & 20 & 30 & 30 & 25 & 30 & 30 & 40 \\ 25 & 25 & 25 & 20 & 10 & 10 & 15 & 15 & 30 & 30 & 20 & 15 & 15 & 10 & 35 & 30 & 20 \\ 25 & 25 & 25 & 5 & 10 & 10 & 15 & 15 & 30 & 30 & 20 & 25 & 15 & 25 & 30 & 30 & 40 \\ 25 & 25 & 30 & 10 & 10 & 10 & 20 & 15 & 30 & 30 & 20 & 30 & 30 & 25 & 30 & 30 & 40 \\ 25 & 25 & 20 & 5 & 10 & 10 & 20 & 10 & 30 & 30 & 20 & 15 & 15 & 10 & 35 & 30 & 40 \\ 25 & 25 & 20 & 5 & 10 & 10 & 15 & 15 & 30 & 30 & 10 & 30 & 30 & 25 & 30 & 25 & 10 \\ 25 & 25 & 20 & 15 & 10 & 10 & 20 & 15 & 30 & 30 & 20 & 15 & 15 & 25 & 35 & 20 & 20 \\ 25 & 25 & 25 & 5 & 10 & 10 & 15 & 10 & 30 & 30 & 20 & 25 & 15 & 20 & 30 & 30 & 10 \\ - & - & - & - & - & - & - & - & - & - & - & - & - & - & - & - & - \\ - & - & - & - & - & - & - & - & - & - & - & - & - & - & - & - & - \\ 25 & 40 & 20 & 20 & 20 & 10 & 20 & 10 & 30 & 30 & 20 & 30 & 30 & 25 & 35 & 30 & 40\end{array}\right]$

\section{Menghitung Matrik Ternormalisasi}

Penelitian ini semua kriteria yang digunakan merupakan kriteria keuntungan (benefit) sehingga penghitungan matriks ternormalisasi dengan rumus:

$$
X i j=\frac{x i j}{M a x i X i j}
$$


Hasil perhitungan dapat dilihat pada matriks di bawah ini.

$X=$

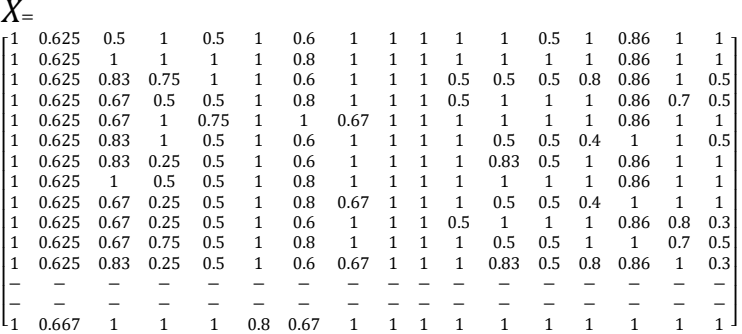

\begin{tabular}{llllll}
\hline 7 & 00032 & & 005 & 15 & Miskin \\
& & & & \\
& & & & \\
& & & & \\
8 & 33021600000 & RT & & \\
8 & 00027 & & 005 & 0,63 & Tidak \\
& & & RW & 7 & Miskin \\
& & & 004 & & \\
8 & 33021600000 & Warsono & RT & & \\
9 & 00065 & & RW & 03 & Miskin \\
& & & 002 & & \\
\hline
\end{tabular}

Penentuan rangking berdasarkan Nilai Qi Tabel .Ranking Nilai Qi

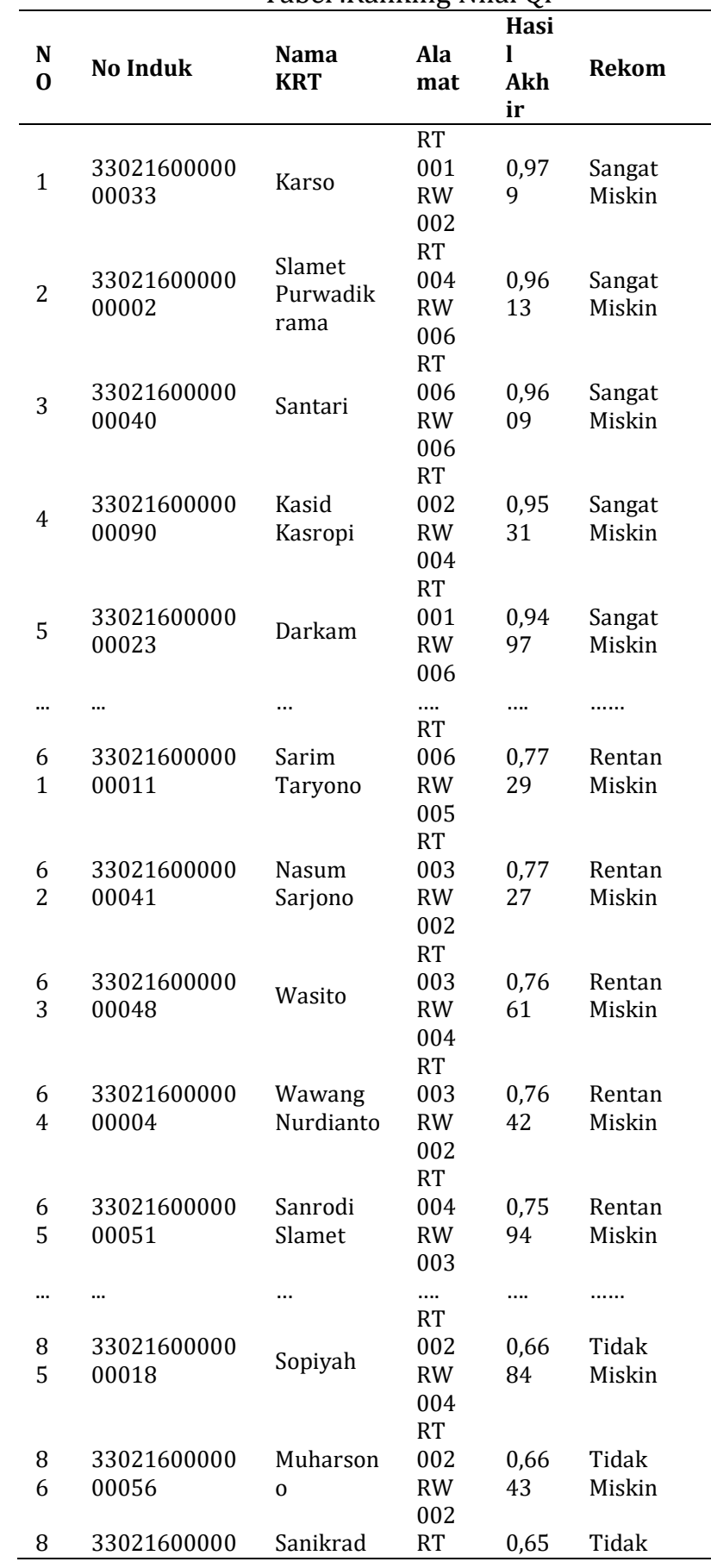

\section{Code}

Implementasi sistem pendukung keputusan rumah tangga miskin ini dengan menggunakan Bahasa Java.

\section{Implementasi}

1. Form Halaman Data Penduduk

Form data penduduk adalah form yang diakses untuk melihat, menambah, mengubah dan menghapus data penduduk.

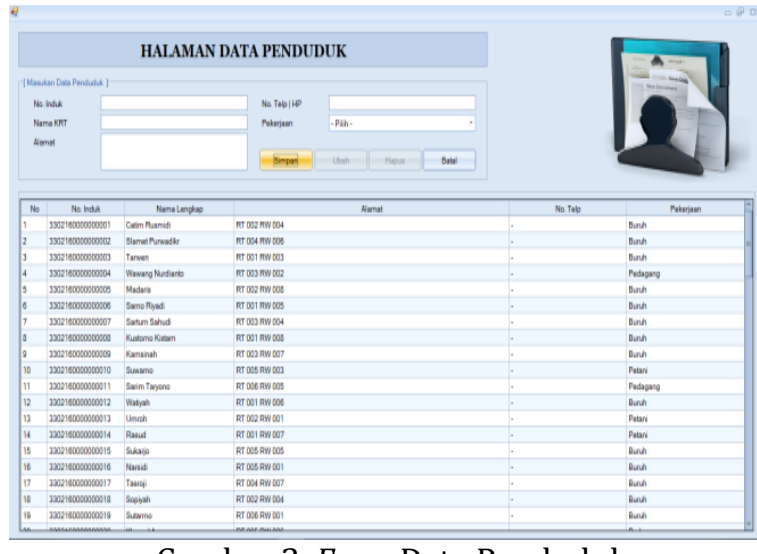

Gambar 2. Form Data Penduduk

2. Form Halaman Data Pembobotan Kriteria Form ini diakses untuk melihat, menambah, mengubah, menghapus dan menentukan bobot kriteria.



Gambar 3. Form Halaman Pembobotan Kriteria 


\section{Form Penilaian Penduduk}

Pada form Penilaian penduduk terdapat dua data yaitu data nilai pemohon dan data hasil normalisasi. Pilih tahun periode seleksi kemudian tekan tombol tampil pemohon. Setelah data tampil kemudian beri nilai sesuai data yang sudah diperoleh.

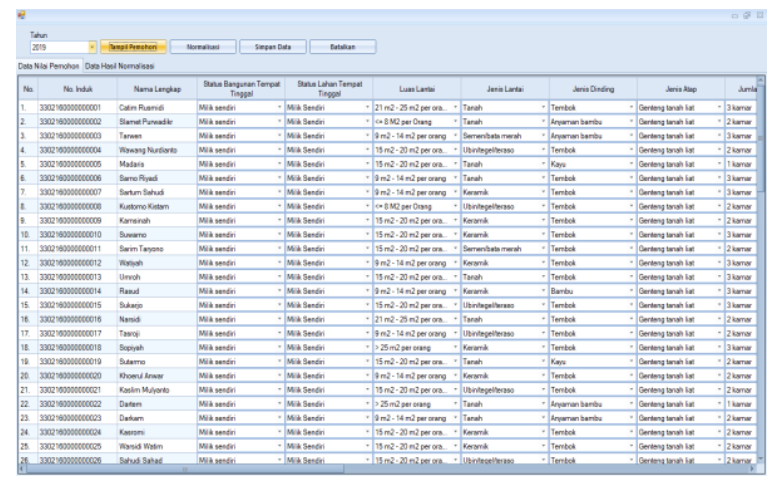

Gambar 4 . Form Data Nilai Pemohom

Setelah semua data nilai penduduk sudah terisi kemudian tekan tombol normalisasi, setelah proses normalisasi selesai tekan tombol simpan data untuk menyimpan data nilai penduduk.

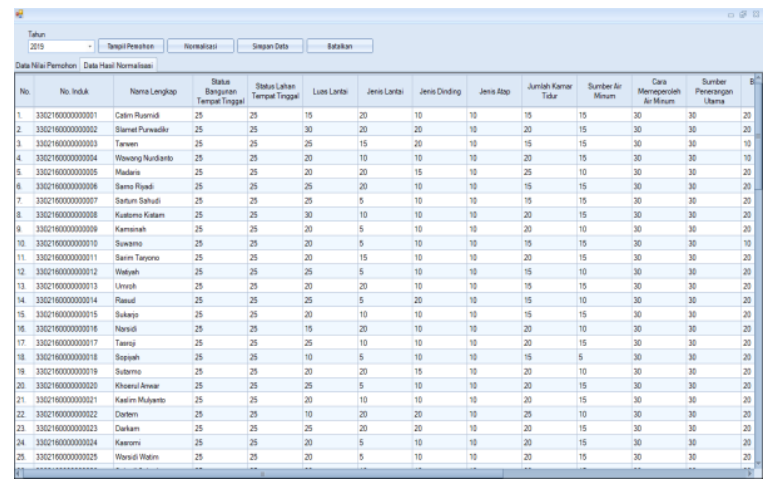

Gambar 5. Form Data Hasil Normalisasi

4. Form Halaman Proses Perhitungan WASPAS

Halaman ini digunakan untuk menghitung nilai data penduduk. Saat form ini diakses maka akan tampil data penduduk beserta nilainya.



Gambar 6. Form Data Nilai Penduduk
Tekan tombol hitung waspada maka akan tampil data normalisasi WASPAS dan Hasil Akhir WASPAS, kemudian tekan tombol simpan untuk menyimpan hasil perhitungan dengan metode WASPAS

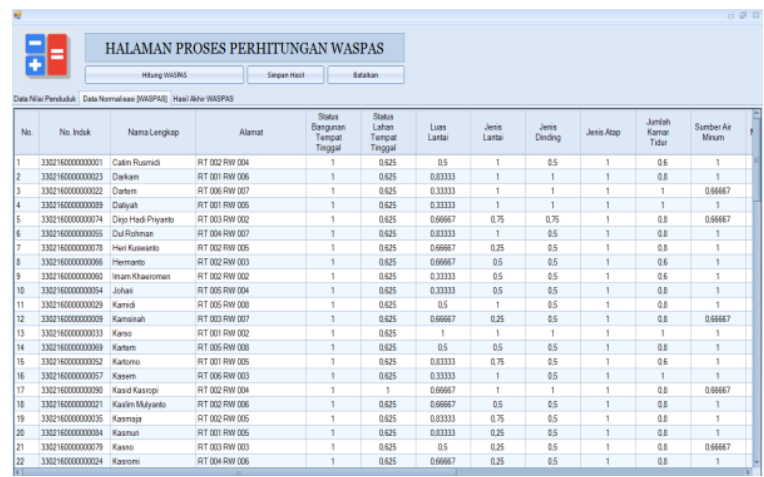

Gambar 7. Form Data Normalisasi WASPAS

Berikutt gambar 8, merupakan hasil Akhir analisis dengan menggunakan metode WASPAS, dimana hasilnya dapat ditampilkan diarsir menggunakan warna-warna.

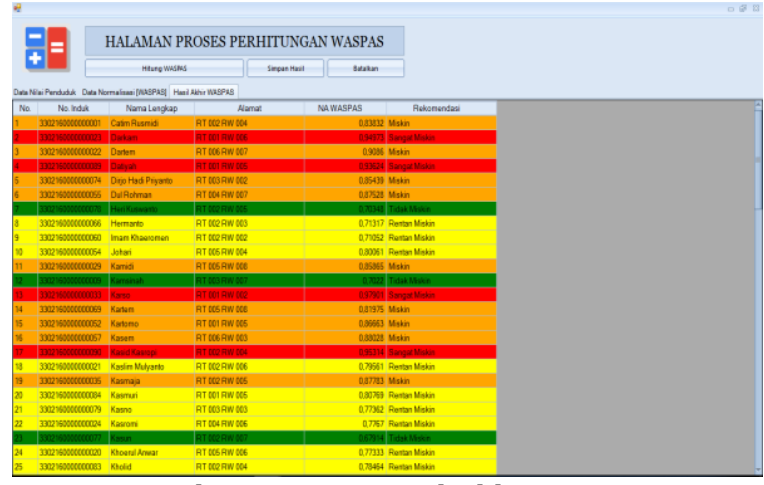

Gambar 8. Form Hasil Akhir Waspas

\section{Halaman Laporan Hasil Perhitungan}

Halaman laporan hasil perhitungan dengan metode WASPAS, untuk kebutuhan laporan instansi dapat langsung di cetak kemedia printer.

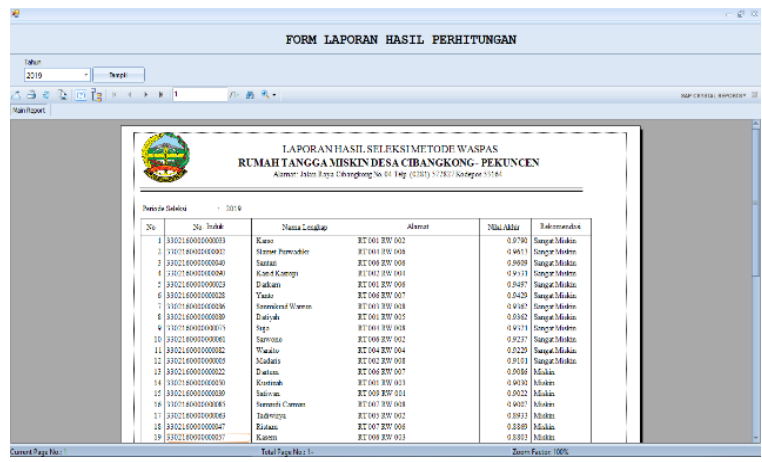

Gambar 9. Form Laporan Hasil Perhitungan 


\section{E. Hasil Penelitian}

Berdasarkan hasil perhitungan dengan menggunakan metode WASPAS, dan diimplementasikan dalam bentuk aplikasi sistem, berdasarkan dari 89 sampel yang diteliti terdapat 12 rumah tangga sangat miskin, 28 rumah tangga miskin, 38 rumah tangga rentan miskin dan 11 rumah tangga tidak miskin. Hasil yang diperoleh dapat dilihat pada grafik di bawah ini:

\section{GRAFIK HASIL PENELITIAN}

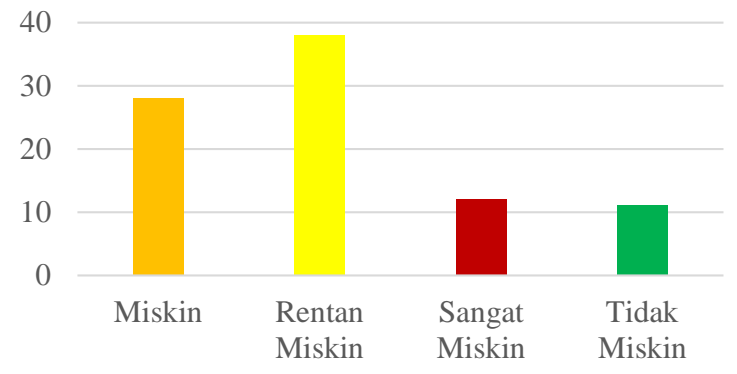

Gambar 15. Grafik Hasil Penelitian

\section{KESIMPULAN}

Berdasarkan dari uraian dan penjelasan serta pembahasan keseluruhan materi pada bab-bab sebelumnya maka dapat diambil kesimpulan antara lain dari jumlah 89 sampel yang dilakukan perhitungan hanya $45 \%$ saja yang layak menerima bantuan program pemerintah. Sistem pendukung keputusan ini mampu mengatasi masalah-masalah yang terdapat dalam penentuan rumah tangga miskin di Desa Cibangkong dan mampu memberikan hasil yang akurat dalam penentuan rumah tangga miskin. Dengan sistem pendukung keputusan metode WASPAS ini pengolahan data akan menjadi lebih efektif dan efisien karena proses penilaian dan pembuatan laporan menjadi cepat. Pegawai hanya memasukan data penduduk, data kriteria dan data penilaian penduduk, sedangkan proses perhitungan dan pembuatan laporan dilakukan oleh sistem.Penerapan metode WASPAS untuk sistem pendukung keputusan dapat memberikan hasil yang maksimal dalam hal pengambilan keputusan dengan cara mengurutkan alternatif penduduk dari yang sangat miskin sampai yang tidak miskin.

\section{DAFTAR REFERENSI}

Handayani, M., \& Marpaung, N. (2018). Implementasi Metode Weight Aggregated Sum Product Assesment (WASPAS) Dalam Pemilihan Kepala Laboratorium. Seminar Nasional Royal (SENAR), (September), 253258.
Indrawati, E. S., Hyoscyamina, D. E., Qonitatin, N., \& Abidin, Z. (2014). PROFIL KELUARGA DISFUNGSIONAL PADA PENYANDANG MASALAH SOSIAL DI KOTA SEMARANG. Jurnal Psikologi Undip, 13(2), 120-132. https://doi.org/https://doi.org/10.14710/jp u.13.2.120-132

irfansyah, puput, \& Sunoto, I. (2015). SISTEM PENDUKUNG KEPUTUSAN SELEKSI SUPPLIER DENGAN PENDEKATAN METODE FIS MAMDANI PADA KOPERASI XYZ. Faktor Exacta, $\quad 8(4), \quad 347-358$. https://doi.org/10.30998/FAKTOREXACTA.V $8 \mathrm{I} 4.505$

Lestari, U., \& Targiono, M. (2017). SISTEM PENDUKUNG KEPUTUSAN KLASIFIKASI KELUARGA MISKIN MENGGUNAKAN METODE SIMPLE ADDITIVE WEIGHTING (SAW) SEBAGAI ACUAN PENERIMA BANTUAN DANA PEMERINTAH (STUDI KASUS: PEMERINTAH DESA TAMANMARTANI, SLEMAN). Jurnal TAM (Technology Acceptance Model), 8(1), 70-78. Retrieved from http://www.ojs.stmikpringsewu.ac.id/index. php/JurnalTam/article/view/97

Lubis, P., Nadeak, B., \& Hondro, R. K. (2017). PENERAPAN METODE ANALITICAL HIERARCHY PROCESS DALAM PENENTUAN WARGA PENERIMA PROGRAM KELUARGA HARAPAN ( PKH ) ( Studi Kasus: Kantor Lurah Tegal Sari Mandala II ). Media Informatika Budidarma, 1(1), 17-23.

Muzakkir, I. (2017). Penerapan metode topsis untuk sistem pendukung keputusan penentuan keluarga miskin pada desa panca karsa II. ILKOM Jurnal Ilmiah, 9(3), 274-281. Retrieved from http://jurnal.fikom.umi.ac.id/index.php/ILK OM/article/view/156

Pardiansyah, A. S. (2015). Audit Tata Kelola Teknologi Informasi Program Studi Sistem Informasi Sekolah Tinggi Manajemen Informatika Dan Komputer ( STMIK) Lombok Menggunakan Framework Cobit. IJSE Indonesian Journal on Software Engineering, 1(1), 17-25.

Saputra, A., Kartini, D., \& Soesanto, O. (2015). RANCANG BANGUN SISTEM PENDUKUNG KEPUTUSAN PENETUAN KELUARGA MISKIN, 
02(01), 84-95.

Saputra, A., Kartini, D., \& Soesanto, O. (2016). RANCANG BANGUN SISTEM PENDUKUNG KEPUTUSAN PENENTUAN KELUARGA MISKIN. KLIK - KUMPULAN JURNAL ILMU KOMPUTER, 2(1), 84-95. https://doi.org/10.20527/KLIK.V2I1.20

Setiani, N. (2017). Studi Tentang Pelaksanaan Pendataan Kelurga Miskin Di Kelurahan Sempaja Selatan Kecamatan Samarinda Utara Kota Samarinda. EJournal Administrasi Negara, 5, 6709-6723.

Sianturi, T. N., Siburian, L., Hutagaol, R. G., \& Sahir, S. H. (2018). Sistem Pendukung Keputusan Pemilihan Pegawai Bank Terbaik Menggunakan Metode Weighted Aggregated Sum Product Assessment ( WASPAS ). SENSASI 2018, 625-631.

Sugiarti, S., Nahulae, D. K., Panggabean, T. E., \& Sianturi, M. (2018). Sistem Pendukung Keputusan Penentuan Kebijakan Strategi Promosi Kampus Dengan Metode Weighted Aggregated Sum Product Assesment (WASPAS), 5(2), 103-108. 